\title{
The Effect of Anti-Tuberculosis Drugs on the Effectiveness of Anti-Retroviral Therapy in HIV-AIDS Patients
}

\author{
Hasriana $^{1}$, Sofa D. Alfian ${ }^{2}$, Tiana Milanda ${ }^{2}$, Rizky Abdulah ${ }^{2}$ \\ 1 Abepura General Hospital, Jayapura, Papua, Indonesia \\ 2 Department of Pharmacology and Clinical Pharmacy, Faculty of Pharmacy, Universitas Padjadjaran, \\ Jatinangor, West Java, Indonesia \\ ${ }^{3}$ Department of Biology Pharmacy, Faculty of Pharmacy,Universitas Padjadjaran, Jatinangor, West \\ Java, Indonesia
}

\begin{abstract}
Tuberculosis is the most common opportunistic infection and a leading cause of death among patients who infected by Humman Immunodeficiency Virus (HIV) in developing countries. The purpose of this study was to determine the effect of anti-tuberculosis drugs (ATB) on the effectiveness of anti-retroviral (ARV) therapy in HIV-AIDS infected patients. This study was a prospective cohort study conducted at outpatient clinic of Abepura Hospital during April-June 2015. The data were taken from medical records, which include CD4 level, gender, age, education and stage of disease. Statistical analysis was performed using bivariate and multiple regression analysis. A total of 28 subjects was included in this study (7 HIV patients and 21 TB-HIV patients). The results of bivariate analysis showed that there was no significant difference on general characteristics of patients using ARV-ATB and without ATB. Gender, age, occupation, education and the stage of disease did not affect the value of CD4 patients $(p>0.005)$. The result from paired t-test showed that there was no significant difference in the level of CD4 cell, before and after treatment using ARV ( $p>0.912)$, while therapy with ARV-ATB showed significant differences $(p<0.002)$. In conclusion, this study showed that the combination of ATB and ARV could increase CD4 level up to $72 \%$. Thus, the use of ATB drugs on ARV patients who infected by TB is recommended to reduce disease burden.
\end{abstract}

Keywords: anti-retroviral therapy, HIV-AIDS, tuberculosis

\section{Introduction}

Acquired Immune Deficiency Syndrome (AIDS) is spectrum of conditions caused by infection of human immunodeficiency virus (HIV). Patients with HIV-AIDS are particularly vulnerable to opportunistic infections due to compromised immune system. The most common opportunistic infection include upper respiratory tract infections, herpes zoster, yeast infections, candidiasis, chronic diarrhea, anemia, cervical cancer, and tuberculosis (TB). ${ }^{1,2}$

Corresponding author: Hasriana. Abepura General Hospital, Jayapura, Papua, Indonesia. Email: hasriana@gmail.com 
TB is an infectious disease caused by Mycobacterium tuberculosis which could attack lungs and other organs. ${ }^{2}$ TB is still the leading cause of death and illness among people living with HIV in developing countries. HIV infection is a risk factor of having active TB. ${ }^{3}$ Construction of a well-established recording and reporting system for TB cases requires private-sector involvement, improvement of recording and reporting for patients' treatment followup, and implementation of electronic-based reporting. ${ }^{4}$

Antiretrovirals can suppress viral progression and increase the number CD4 up to 10,000 times in people infected with HIV. ${ }^{5}$ In Indonesia, the prevalence of HIV/AIDS is relatively high. From April 1987 to December 2013, there were 127,416 HIV/AIDS cases and 52,348 AIDS cases in Indonesia. The key populations most affected by HIV in Indonesia are sex workers, with HIV prevalence of $5.3 \%$, gay men, with HIV prevalence of $25.8 \%$, people who inject drugs, with HIV prevalence of $28.76 \%$, transgender people, with HIV prevalence of $24.8 \%$ and prisoners, with HIV prevalence of $2.6 \% .^{6-9}$

Patients with HIV/AIDS in Papua in 2012 who obtained ARV therapy were 3656 people. Data obtained from Abepura Hospital Voluntary Conseling Test (VCT) showed that in 2012 the number of HIV patients underwent ARV treatment was $68.6 \%$ of the patients. $^{5}$

Pulmonary TB is the most common opportunistic infection in people with HIV. From a total of 1.7 million people who died of TB in 2009, 400,000 were HIV patients. Among 9.4 million new TB cases in 2009,

Table 1. General characteristics of subjects

\begin{tabular}{lccc}
\hline \multirow{2}{*}{ Characteristics } & \multicolumn{2}{c}{ Treatment } & \multirow{2}{*}{ P-value } \\
\cline { 2 - 3 } & ARV (n=7) & ATB-ARV (n=21) & \\
\hline Sex & 3 & 9 & $1.0^{*}$ \\
Male & 4 & 12 & \\
Female & & & $0.852^{* * *}$ \\
Age (years) & $26.9(7.8)$ & $28.7(10.8)$ & \\
Mean (SD) & 25 & 25 & \\
Median & $18-38$ & $18-53$ & $1.0^{*}$ \\
Range & 1 & 2 & \\
Occupation & 6 & 19 & $0.104^{* *}$ \\
Worker & & & \\
Jobless & 4 & 4 & \\
Education & 3 & 12 & $0.082^{* *}$ \\
Elementary & 0 & 5 & \\
Secondary & & 2 & \\
High & 3 & 14 & \\
Disease stage & 4 & 5 & \\
II & 0 & & \\
III & & & \\
IV & & & \\
\hline
\end{tabular}

* Fisher's exact $* *$ Chi-square ***Mann-Whitney 
Table 2. CD4 before and after treatment with ARV or ATB-ARV

\begin{tabular}{|c|c|c|c|}
\hline Variable & $\begin{array}{c}\text { CD4 cell } / \mathbf{m m}^{3} \\
\text { Initial (SD) } \\
\end{array}$ & $\begin{array}{c}\mathrm{CD} 4 \mathrm{cell} / \mathrm{mm}^{3} \\
\text { End }(\mathrm{SD})\end{array}$ & P-value* \\
\hline $\operatorname{ARV}(n=7)$ & $436.4(128.6)$ & $437.9(144.0)$ & 0.912 \\
\hline ATB-ARV $(n=21)$ & $170.5(111.2)$ & $214.6(100.8)$ & 0.002 \\
\hline
\end{tabular}

1.2 million were TB in HIV patients. ${ }^{10-12}$ Treatment of HIV and TB should be simultaneously effective, as this may affect the prognosis of the disease.

ARV therapy can reduce the risk of TB by $70-90 \%$ in HIV-infected patients and can suppress the virus in plasma and normalize CD4 T-cells. ${ }^{13}$ CD4 tests in HIV-AIDS patients are usually performed at 2 weeks, 3 months and every 6 months after starting the ARV. ${ }^{14}$ Interaction between ATB and ARV such as between rifampicin and efavirenz or nevirapine could decrease bioavailability of ARV. ${ }^{15}$ However, limited information was known regarding the clinical effectiveness of the use of combination of ARV-ATB among HIV-AIDS patients infected with TB.

The purpose of this study was to determine the effect of ATB on the effectiveness of ARV in HIV/AIDS patients in Abepura General Hospital of Jayapura.

\section{Methods}

This was a prospective observational cohort study, comparing theurapetic effect of two treatment groups, i.e., ARV group and ATBARV group during April-June 2015. This research has obtained ethical approval from Abepura General Hospital, Jayapura, with reference number of $008 / \mathrm{KM} / \mathrm{IV} / 2015$.

The inclusion criteria in this study were:

1. Newly diagnosed HIV-AIDS patients with or without TB.

2. Aged $\geq 18$ years old.

3. Had complete medical records.

We excluded patients who refused to participate in the study.

General characteristics of subjects, such as

Table 3. The effect of ATB on the effectiveness of ARV

\begin{tabular}{lcccc}
\hline \multicolumn{1}{c}{ Variable } & Coefficient & SE(B) & T-value & P-value \\
\hline I. Initial model & & & & \\
$\quad$ Initial CD4 & 0.788 & 0.146 & 5.394 & $<0.002$ \\
Stage & -12.221 & 29.862 & 0.409 & 0.686 \\
Age & 1.177 & 1.383 & 0.851 & 0.404 \\
ATB & 0.012 & 0.034 & 0.357 & 0.724 \\
& & & & \\
II. End model* & 0.798 & 0.073 & 10.884 & $<0.002$ \\
$\quad$ End CD4 & 91.144 & - & - & \\
Constant & & & & \\
$* \mathrm{r}^{2}(\%)=72 \% ; \mathrm{p}<0.001$. & & &
\end{tabular}


sex, age, education, occupation, and disease stage were obtained. CD-4 value at initial and after three months of treatment were compared. Statistical analysis was performed using bivariate and multiple regression analysis. P-value $<0.05$ defined statistical significance.

\section{Results and Discussion}

We included 28 subjects in this study, 21 patients received ATB-ARV therapy, while 7 patients only received ARV. General characteristics of the subjects can be found in Table 1. No significant difference observed between those receiving ATB therapy and those who did not ( $p>0.05)$.

The majority of the subjects in this study were women. A study in Rwanda showed that TB and HIV affected all ages and both sexes. ${ }^{16}$ Another study showed that women are more vulnerable than men. ${ }^{16-18}$ The results of a study in Nashville Mexico showed that TB patients tend to occur in men, blacks and heterosexuals. ${ }^{19,20}$ Age is an influential characteristics due to its relation with immune system condition and comorbidities. ${ }^{21}$

Therapy with ARV alone did not showed significant difference on CD-4 before and after the treatment ( $p>0.912)$. However, the opposite result was observed in ATB-ARV group $(p<0,002)$. We found that the combination of ATB and ARV did not decrease therapeutic effect of ARV, even significantly increase its effectiveness.

However, these finding should be interpreted with caution since other factors can play a role in the effectiveness of ARV, such as the presence of other comorbities, drugs metabolism, the use of concomitant medication, and adherence to medication. ${ }^{18}$

A multivariate analysis of initial and end CD4 value in OAT-ARV group showed significant $(p<0.05)$ difference with linear regression equation $y=0.798 x+91.144\left(\mathrm{r}^{2}=72 \%\right)$. In this study, we estimated that interaction between ARV and ATB could be reduced by setting the time of consumption of both drugs. ATB was taken 1 hour before meal, while ARV 1 hour post meal and at night. Drugs interaction could result in increase/ decrease of bioavailability and therapeutic effect of drugs and caused side effects. ${ }^{20}$

Several studies showed that the major cause of death in HIV-AIDS patients was due to infection, malignancy, liver disorders, heart problems, respiratory disorders, renal failure, and side-effect related drugs. Another study found that patients with HIV and TB had $15 \%$ higher risk of death compared to HIV patients without TB. Combination of TBHIV treatment is an obligatory step to control disease and reduce disease burden. ${ }^{2}$ The results of the study in Rwanda showed that TB-HIV patients who were given appropriate drugs, had improvement in medical conditions $(33.3 \%)$, with decreasing death rate $(20 \%) .{ }^{19-}$ 24

\section{Conclusion}

This study showed that the combination of ATB and ARV could increase CD4 level up to $72 \%$. Thus, the use of ATB drugs on TBcomplicated HIV patients is recommended.

\section{Acknowledgement}

None declared

\section{Funding}

This study was not funded by any source of grants

\section{Conflict of Interest}

The authors declared no potential conflicts of interest with respect to the research authorship, and/or publication of this article 


\section{References}

1. UNAID. Word AIDS Day Report, Geneva: UNAID. 2012

2. Richardson ET, Grant PM, Zolopa AR. Evolution of HIV treatment guidelines in high and low-income countries: converging recommendations. Antiviral Research. 2014;103:88-93.

3. ManosuthiW,OngwandeeS,Bhakeecheep S. Guidelines for antiretroviral therapy in HIV-1 infected adults and adolescents. AIDS Research and Therapy. 2015;12:12.

4. Rosma A, Yamazaki C, Kameo S, Herawati MDH, Ruslami R, Raksanagara $\mathrm{A}$, et al. Factors influencing private practitioners to report tuberculosis cases. Pharmacology and Clinical Pharmacy Research. 2016;1(1):1-10.

5. Dejesus E, Rockstroh JK, Henry K, Molina JM. Coformulated elvitegravir, cobicistat, emtricitabine, and tenofovir disoproxil fumarate versus ritonavirboosted atazanavir plus co-formulated emtricitabine and tenofovir disoproxil fumarate for initial treatment of HIV-1 infection: a randomised, double-blind, phase 3, non-inferiority trial. Lancet. 2012;379:2429-2438.

6. Cohen MS, Shaw GM, McMichael AJ, Haynes BF. Acute HIV-1 Infection. New England Journal of Medicine. 2011;364(20):1943-1954.

7. Golub JE, Saranceni V, Cavalcante SC, Pacheco AG, Moulton LH, King BS, et.ol. The impac of antiretroviral therapy and isoniazid preventive therapy on tuberculosis incdence in HIV-infected patients in Rio de Janeiro, Brazil. AIDS. 2007;21:1441-1448

8. Stocman JK, Lucea MB, and Campbell JC. Forced sexual initiation, sexual intimate partner violence and HIV risk in women. AIDS and Behavior. 2013;17(3): 832-847.

9. Eshleman SH, Khaki L, Laeyendecker
$\mathrm{O}$, et al. Detection of individuals with acute HIV-1 infection. Journal of AIDS. 2009;52:121-124.

10. Klot JF, Wira CR. Sexual violence and genital injury: the physiology of HIV transmission risk. American Journal of Reproductive Immunology. 2012. 69;2:310.

11. Stewart A, Carusone SC. Causes of death in HIV patients and the evolution of an AIDS hospice: 1988-2008. AIDS Research and Treatment. 2012;39(4):6467.

12. Walth M, Lancaster J, Odendaal R, Davis JG. Serious treatment related adverse drug reactions amongst anti-retroviral naive MDR-TB patients. PloS One. 2013;8(4):58-69.

13. Thompson MA, Aberg JA, Hoy JF. Antiretroviral treatment of adulth HIV infection: 2012 recommendations of the International Antiviral Society-USA panel. Journal of the American Medical Association. 2012;38(4): 387-402.

14. Pillay P, Ford N, Shubber Z, Ferrand RA, Outcomes for efavirenz versus nevirapine-containing regimens for treatment of HIV-1 infection. PloS One. 2013;8(7):99-105.

15. Fernandez B, Montoya-Ferrer A, Sanz BA. Tenofovir nephrotoxicity. AIDS Research and Treatment. 2011;11(35):9098.

16. Maartens G, Celum C, Lewin SR. HIV infection: epidemiology, pathogenesis, treatment, and prevention. Lancet. 2014;384(9939):258-271.

17. Arts EJ, Hazuda DJ. HIV-1 antiretroviral drug therapy. Perspective in Medicine. 2012;2(4):a007161.

18. Rwanda Biomedical center. National Annual Report July 2011-Juni 2012, http;// www.rbc.gov.rw/spip.php?article37014k. [accessed on February 2017].

19. Kwan CK, Ernst JD. HIV and tuberculosis: 
a deadly human syndemic. Clinical Microbiology Reviews. 2011;24(2):351376.

20. Bruchfeld J, Correia-Neves M, Källenius G. Tuberculosis and HIV Coinfection. Cold Spring Harbor Perspectives in Medicine. 2015;5(7):178-181.

21. Abdool Karim SS, Churchyard GJ. HIV infection and tuberculosis in South Africa: an urgent need to escalate the public health response. Lancet. 2009. 374:921-933.

22. Abgrall S., Del Giudice P., Melica G, Costagliola D. HIV-associated tuberculosis and immigration in a highincome country: incidence trends and risk factors in recent years. AIDS. 2010; 24:763-771.

23. Aberg JA. Primary care guidelines for the management of persons infected with human immunodeficiency virus. Clinical Infectious Diseases. 2009;49:651-681.

24. Abdool KS. Timing of initiation of antiretroviral drugs during tuberculosis therapy. New England Journal of Medicine. 2010;362:697-706. 